TAO, Vol. 14, No. 4, 445-467, December 2003

\title{
The Cloud Radiative Forcing over Asian-Pacific Summer Monsoon Region
}

\author{
Wen-Shung Kau ${ }^{1, *}$, Chi-Hua Wu ${ }^{1}$, and Chih-Hua Tsou ${ }^{2}$ \\ (Manuscript received 12 February 2003, in final form 6 October 2003)
}

\begin{abstract}
The strength of the Asian-Pacific summer monsoon (APSM) is associated with intensities from two major convective heat sources centered primarily over the Bay of Bengal (BB) and the western North Pacific (WNP). Because of the complexity of the APSM, especially over WNP, almost all of the general circulation models (GCMs) cannot simulate the climate features around the Asian monsoon region satisfactorily. This could be due to the inability of the GCMs to simulate correct cloud formations and radiative properties of clouds. In this study we will focus on the role of clouds and cloud radiative forcing (CRF) in the evolution of the APSM.

Our study relies on radiative fluxes at the top of the atmosphere from the Earth Radiation Budget Experiment (ERBE) and cloud data from the International Satellite Cloud Climatology Project (ISCCP-D1) to inquire about some common properties of CRF in the four regions of East and Southern Asia: the BB, South China Sea (SCS), WNP, and Central China (CC).

During the APSM, we arrived at the following conclusions: After the onset of the summer monsoon, there is a lower OLR and a larger high cloud fraction with heavy and persistent rainfall in the $\mathrm{BB}$ throughout the whole summer. At the same time, extremely dense clouds (with thick optical depth) reaching into the higher atmosphere associated with strong convergence in the lower layers and divergences over the upper troposphere persistently occur in the BB. The strong dynamic force associated with closed spaced convective updrafts, as in $\mathrm{BB}$, can result in a significant negative CRF (as low as $\mathbf{- 7 0 ~} \mathrm{W} \mathrm{m}^{-2}$ ). However, WNP and SCS are different from BB, not only in the CRF but also in the cloud's temporal and spatial distributions. $A$ brief recess of deep convection occurs in mid-July in WNP and SCS, which causes the magnitude of precipitation, cloud amount, optical depth and CRF
\end{abstract}

\footnotetext{
${ }^{1}$ Department of Atmospheric Sciences, National Taiwan University, Taipei, Taiwan

2 Department of Earth Sciences, National Taiwan Normal University, Taipei, Taiwan

${ }^{*}$ Corresponding author address: Prof. Wen-Shung Kau, Department of Atmospheric Sciences, National Taiwan University, Taipei, 106, Taiwan; E-mail: wen@ wen.as.ntu.edu.tw
} 
for the entire summer to average less than in BB. In both WNP and SCS, individual elements within the convective cloud system show a wide range of net radiative forcing (from the thick anvil clouds near convective cores to thin cirrus clouds near the edges of the anvil cloud) which produces a net CRF of near zero when averaged over the convective cloud system.

Through spectral analysis of high cloud amounts, we can find that over $\mathrm{BB}$, the highest power is in the period around 75 days, which is the intraseasonal timescale. While over WNP, the leading spectral peaks are at 1020 days and 8-9 days. These two dominant frequencies are definitely related to the fast annual cycle (proposed by LinHo and Wang). Failure to simulate correctly these two frequencies may be the primary reason why the GCMs exhibit great difficulty in reproducing correct precipitation in the WNP. The cloud structures and CRF in CC are very different from the oceanic regions in our analysis and where mid-low level clouds with thick optical depths play more of a role than does the high, thin cloud.

(key words: Asian-Pacific summer monsoon, Cloud radiative forcing, GCMs, ISO, fast annual cycle)

\section{INTRODUCTION}

Earth's climate system is driven by a radiative energy, balanced between the solar shortwave radiation absorbed by Earth and the thermal infrared radiation emitted upward into space. Clouds have been shown to be one of the most important factors regulating our current climate system and future climate change. Cloud forcing exhibits significant seasonal and geographic variability, in part due to the fact that cloud effects are different for different cloud regimes (Hartmann and Short 1980); however, little progress has been made in the climatology of cloud-radiation interactions in the atmosphere because of difficulties in accurately estimating its radiative flux before 1985. Now, the Earth Radiation Budget Experiment (ERBE) provides the first accurate estimate of shortwave and longwave radiative fluxes at the top of atmosphere (TOA) with or without the cloud modulation, while the International Satellite Cloud Climatology Project (ISCCP) provides us with basic information on cloud parameters to coordinate research on techniques for inferring the physical properties of clouds and cloud-radiation interactions.

In recent years, observations from earth-orbiting satellites have been greatly improved in quality and are available to improve our understanding of the cloud-radiation interaction and the earth's radiation budget. The concept of cloud radiative forcing (CRF), which measures the difference between the cloud-free radiative fluxes and the average of all-sky observation, has been used extensively to study the impact of clouds on climate. Wielicki et al. (2002) presented new evidence gathered from over two decades of accurate satellite data, showed that the tropical TOA radiation energy budget is much more dynamic and variable than previously thought. Their results indicated that the variations in the radiation budget were caused by 
changes in mean tropical cloudiness. Further, they also pointed out that the results of several current climate model simulations failed to predict that this largely observable variation in the tropical energy budget was caused by a lack of variability in cloud modeling. With the same data set, Chen et al. (2002) found that the cause of radiative flux was associated with a decadaltime-scale strengthening of the tropical Hadley and Walker circulations. They showed that the equatorial convective regions have intensified in upward motion and moistened, while both the equatorial and subtropical subsidence regions became drier and less cloudy.

The influences of CRF on atmospheric circulations have been studied in many papers. Neelin and Held (1987) showed that the strength of the low-level convergence in the tropical convergence zones is directly proportional to the net radiation at the TOA. Bergman and Hendon (2000) pointed out that the CRF contributes about $20 \%$ to the magnitude of low-latitude maritime circulations, both at the surface and in the deep troposphere. They also showed that CRF tends to have a stronger influence in the lower troposphere than at upper levels, and it influences local circulation more than remote ones. As a result, CRF systematically strengthens low-latitude circulations over the oceans. Tian and Ramanathan (2002) demonstrated that during deep convection periods, high clouds over the inter-tropical convergence zone (ITCZ), the South Pacific convergence zone (SPCZ), and the warm pool (WP) exert a positive CRF of about $70\left(\mathrm{~W} \mathrm{~m}^{-2}\right)$ within the atmosphere, while a negative CRF of about $-70\left(\mathrm{~W} \mathrm{~m}^{-2}\right)$ is found at the surface. They also pointed out that the atmospheric CRF provides the major energy source for balancing the divergence of moist static energy (MSE) transport (from the ITCZ, the SPCZ, and the WP to the subtropics and the cold tongue) by the large-scale atmospheric circulation.

The studies of the physical properties of clouds and cloud radiation interactions have also been emphasized. Weare (1997a) and Weare (1997b) showed that long-wave cloud radiative forcing (LWCRF) is strongly related to high cloud density, and shortwave cloud radiative forcing (SWCRF) is better related to high cloud density and high cloud optical depth. While low clouds make little contribution to LWCRF, they make a substantial contribution to SWCRF. In highly convective regions in the Tropics, the albedo effect and outgoing long-wave radiation (OLR) are significantly influenced by variations in cloud structure as well as cloud amount (Hartmann and Doelling 1991). Pai and Rajeevan (1998) examined the Net cloud radiative forcing (NCRF) at the TOA by using ERBE data. They demonstrated that the variations in CRF are strongly correlated with changes in high cloud fraction, but weakly correlated with changes in low or middle clouds. In the tropical deep-convection regions, a high cold cloud will have a greater LWCRF than a low warm cloud because it emits less long-wave radiation into space, and thus provides greater greenhouse warming. Kiehl (1994) suggested that the near cancellation effect is dominated by the tropical tropopause height. In many papers published since, it has been assumed that a near cancellation between the LWCRF and SWRCF at the TOA is a fundamental feature of deep convective systems in the Tropics. However, this conclusion was invalidated by Rajeevan and Srinivasan(2000). They pointed out that the NCRF at the TOA over the Asian monsoon region is largely negative during the summer season. The large negative NCRF was explained due to presence of optically thick high clouds. They have also shown that the combination of high cloud fraction and high optical depth occurs in the Asian monsoon region only. In the other deep-convective regions of the Tropics, high clouds 
with large optical depths are present, but cannot cover a large area. Recently, Hartmann et al. (2001) used ERBE and ISCCP data in conjunction with a radiation transfer model (Fu and Liou 1993) to estimate the effect of various cloud types on the TOA radiation budget in a tropical convective region. Cess et al. (2001) also used Fu and Liou's (1993) model to show the dependence of CRF on cloud altitude and cloud optical depth.

Studies with ocean general circulation model (GCM), atmospheric GCM (AGCM), and coupled ocean-atmospheric GCM (CGCM), all show that simulated tropical circulations are sensitive to CRF (Randall et al. 1989; Slingo \& Slingo 1991; Sherwood et al. 1994; Ma et al. 1996; Kessler et al. 1998). Allan et al. (2002) pointed out that changes in a dynamic regime and its anomalous structure, as in the $1998 \mathrm{El}$ Niño, are well simulated by the Hadley Center climate model, forced by the observed SSTs. Unfortunately, the LWCRF and SWCRF are poorly simulated. Allen et al. have argued persuasively for the need of an improved representation of CRF before cloud feedback studies simulated by climate models can be used. Ma et al. (1996) prescribed enhanced low cloud fractions in the subtropical eastern Pacific in a CGCM experiment. That change corrected the warm bias in the southeastern Pacific. This result suggests that clouds are indeed important for ocean-atmospheric coupling in the eastern Pacific, and that better cloud parameterizations might improve simulations by CGCM.

Although CRF in every region has not been completely understood, its influence on the global or local energy balance, temperature distribution and dynamic circulation should not be ignored, especially over the Asian Pacific Summer Monsoon (APSM) region. Observations indicate that the APSM shows distinctive characteristics of persistent heavy rainfall and exhibits huge regionality in their climatology and interannual variability, in particular between the Indian and western North Pacific (WNP) summer monsoon (Tao and Chen 1987; Wang et al. 2001; Wang and LinHo 2002). From their geographic setting relative to the continentocean distribution, we would expect that the variability of the Indian and WNP monsoon might be dissimilar.

The APSM system, sensitive to seasonal change, is particularly renowned for its abundance of singularities (LinHo and Wang 2002; Lanzante 1983). As pointed out by LinHo and Wang (2002), the APSM climatology is characterized by a slowly evolving seasonal transition (slow annual cycle, SAC) superimposed upon two fast annual cycles. The SAC reflects the large-scale seasonal transition of continent and ocean that forces more rapid changes of the fast annual cycles. The fast annual cycles are composed mainly of two monsoon outbreaks. When the first cycle reaches its peak in mid-June, a convection zone rules an area from the Arabian Sea to the greater Indochina Peninsula. The primary rain movements are packed within the Arabian Sea and the Bay of Bengal. The cloud clusters propagate to the east in the tropical region, then detour north toward the west coast of India and the head of the Bay of Bengal. When the second cycle begins, the convection center shifts to the WNP just east of the Philippine Islands. At the same time, the major cloud movement switches from a northeastward direction in the Indian Ocean to a northwestward direction. LinHo and Wang also showed that the ratio of fast annual cycle (FAC) to SAC reveals that the SAC dominates in the BB, indicating that the Indian monsoon has a strength dominating the first cycle, since it extracts energy from a larger and more compact monsoon circulation; whereas, during the second cycle, a giant oceanic cyclone intensifies over the western North Pacific. Thisíucean monsoon gyre 
incubates numerous tropical cyclones and the FAC has a stronger presence than the SAC in the western North Pacific.

In light of the results obtained by LinHo and Wang (2002), Wang and LinHo (2002), about the time-space structure of the APSM, to reveal further the special features of clouds and CRF more thoroughly, as did Wang et al. (2003), we will focus our study on the APSM to inquire about some common properties of CRF in various regional monsoon systems such as: Bay of Bengal (BB), South China Sea (SCS) and WNP. The results will provide an observational basis for validating the existing AGCMs and climate system models simulating the APSM. The data used for the CRF and cloud analysis are given in section 2, while analyses of the cloud amount, CRF and their relations to dynamical circulation in the APSM region are shown in section 3 , and the results and a discussion are presented in section 4.

\section{DATA}

ERBE data gathered from January 1985 to December 1989 consisted of all-sky and clearsky long-wave and shortwave radiation fluxes at the TOA, temporally averaged into monthly means and spatially averaged into $2.5 \times 2.5$ latitude-longitude grids. A detailed analysis of the uncertainties in the ERBE data has been made by Rieland and Raschke (1991), but the impact of random errors become negligible after time and space averages are calculated ( $\mathrm{Yu}$ et al. 1999).

The ISCCP provides cloud parameters, such as cloud height, optical depth and amount from a global network of geostationary weather satellites and at least one polar orbiting satellite. The ISCCP data includes B3, BT, CX, C1, C2, DX, D1 and D2 data sets.

The D1 data used in this study is computed into a daily mean average composition of DX (a mapped pixel, $3 \mathrm{hrs}$, global) data. Its grid interval is $2.5 \times 2.5$ degrees from 1 July 1983 to 31 December 1999 or longer. The D2 data is the monthly mean average. As the normalization of ISCCP, D2 data has been more complete in distribution of space than the D1 data. There are 202 parameters in the D1 data and 130 parameters in the D2 data. Its frequency of wave band measurement of the satellites, including IR (11), VIS (0.6) and NI (3.7) respectively; the parameters include total, high, middle, and low cloud amount, cloud top pressure, and cloud optical depth. The cloud types of ISCCP had been modified from the CX data to the DX data, including 9 types, with 8 layers; 50, 180, 310, 440, 560, 680, 800 and $1000 \mathrm{mb}$. High cloud top pressure is smaller than or equal to $440 \mathrm{mb}$, middle cloud is between $680 \mathrm{mb}$ and $440 \mathrm{mb}$, and low cloud is larger than or equal to $680 \mathrm{mb}$. ISCCP data were also used to examine cloud optical depth and cloud top pressure to get 9 types of clouds: cirrus, cirrostratus, deep convection (high cloud), altocumulus, altostratus, nimbostratus (middle cloud), cumulus, stratocumulus and stratus (low cloud), as represented in Fig. 1. We can obtain these data sets directly from the United States CERES website (http://asd-www.larc.nasa.gov/ceres/ASDceres.html) or the ISCCP website (http://isccp.giss.nasa.gov), which also provides an on-line download service. In this study, we have relied upon three cloud parameters from the ISCCP-D1 data set with regard to cloud amount, optical depth and cloud top pressure.

In addition to clouds and radiation fluxes, CMAP (Climate prediction center Merged 
Analysis of Precipitation) pentad mean precipitation, daily OLR analyzed from the Climate Diagnostic Center and the European Center for Medium-Range Weather Forecasts reanalysis products (to show the circulation and cloud properties over APSM) are used in this study. For this study, we matched each variable to the ERBE data set for the same temporal period and the same spatial grids.

\section{CLOUD AMOUNTS, OLR, CRF AND CIRCULATIONS}

The APSM can be divided into three regimes, the Indian monsoon (IM), the East Asian monsoon (EAM), and the western North Pacific monsoon (WNPM) (Wang and LinHo 2002). The IM and WNPM are tropical monsoons, while the EAM is a subtropical monsoon. Note that the WNPM is much more variable than the IM. The convection in WNP is also more directly affected by the Pacific Sea Surface Temperate (SST) anomaly than the convection over the Bay of Bengal (Wang et al. 2001). Wang et al. (2002) examined the precipitation rate averaged over the IM and WNPM regions during APSM period from 11 AGCMs. They pointed out that over the IM region nearly all models overestimated the summer precipitation rate. As a consequence, the all-model ensemble mean has a systematic positive bias in summer rainfall from May to September, which is particularly large in June and July. The spreading among the models is moderate. On the other hand, over the WNPM region, the all-model ensemble mean annual cycle matches the smoothed CMAP climatology to some extent, but none of the models were close to the all-model mean. Thus, the spreading among the models is nearly triple

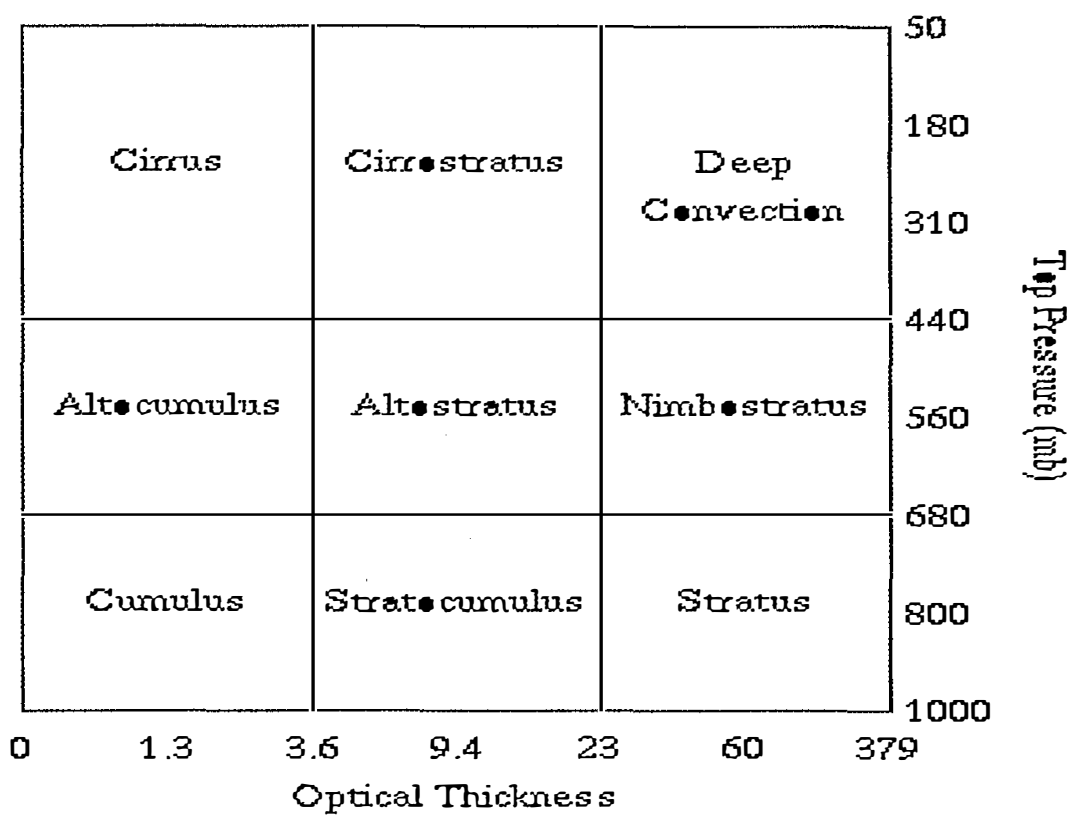

Fig. 1. ISCCP cloud type map (according to cloud top pressure and optical thickness) 
that over the IM region. This deficiency is consistent with the result of Kang et al. (2001) in that the monsoon trough over the WNP were misrepresented in nearly all models. The AGCMs exhibit great difficulty in reproducing correct climatology in WNP than over the Indian region. This inept performance is associated with the fact that over the BB, SCS and WNP, the observed rainfall anomalies tend to negatively correlate, whereas the simulated rainfall anomalies positively correlate with local SST anomalies. Wang et al. attribute this opposite tendency to the neglecting of monsoon-ocean interaction in the AGCM. The reasons for this can be also explained as the inadequate simulation of cloud formations and the radiative properties of clouds in AGCM. Clouds are important because they both affect and are affected by variations of SST. Clouds affect SST by redistributing radiative energy throughout the climate system. Clouds also affect SSTs indirectly by altering atmospheric heating rates. That source of atmospheric heating influences surface winds, which influence wind-driven surface fluxes, which influence SST. Thus, if a GCM contains realistic cloud parameterizations and cloud/radiation scheme, it should replicate the substantial cloud redistributions with the observed climatology, and realistically reproduce the dynamic and thermodynamic state of the atmosphere.

On the basis of the preceding discussion, this study is designed to examine the CRF and its relationship with various cloud types on summer monsoon oceans of persistent convective cloud such as BB, SCS and WNP. The results are compared with central China (CC) to address the differences of cloud properties and CRF between land and ocean.

\subsection{Cloud Amounts, OLR and CRF}

The spatial patterns of the NCRF, LWCRF, deep-convective cloud amounts, and precipitation for the period June-August 1985-1989 are shown in Fig. 2. For the three summer monsoon oceans of the BB (85-95 E, 10-20 N), SCS (110-120 E, 10-20 N) and the WNP (125-135 E, $10-20 \mathrm{~N}$ ), we find negative NCRF with its magnitude exceeding $-40 \mathrm{~W} \mathrm{~m}^{-2}$ over the north BB (Fig. 2a), while NCRF in SCS and WNP are also negative. However, their absolute values are much smaller $\left(-10 \mathrm{~W} \mathrm{~m}^{-2}\right)$. Thus, we can infer that, in general, there is a near zero possibility of NRCF in many areas of the Tropics; however, a large negative value NCRF is observed over BB. The spatial pattern of Figs. $2 b, d$ are very similar and indicates that the ocean regions of BB, SCS and WNP all have large LWCRF and precipitation, whereas CC has a much smaller LWCRF as well as less precipitation than the three summer monsoon oceans. From Fig. 2c, we find that both the BB and $\mathrm{CC}$ have larger amounts of deep-convective clouds (greater than 10\%) than other areas. After viewing Fig. 2, we can conclude that BB has a large negative NCRF, LWCRF, more deep convective clouds, and heavy precipitation. On the other hand, both SCS and WNP have similar cloud types and cloud radiation properties associated with heavy precipitation. However, their NCRF is near zero, which is very different from BB. While CC has a large negative NCRF, large amount of deep convective cloud, and small LWCRF associated with small precipitation.

To aid in the understanding of the difference of NCRF between BB and WNP, we have plotted the 1985-1989 mean annual cycle of OLR, precipitation, cloud amount, optical depth and NCRF averaged over BB, CC, SCS and WNP areas. Figs. 3a, b show the daily time series of OLR and precipitation, total cloud amount (TCA), high cloud amount (HCA) and mid-low 
(2a) NCRF ( w/m*m ) 85 89 JUA

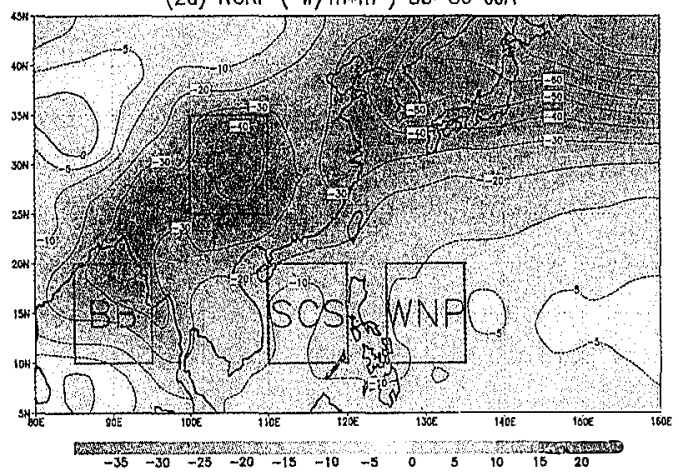

(2c) Deep convection ( \% ) 85 89 JJA

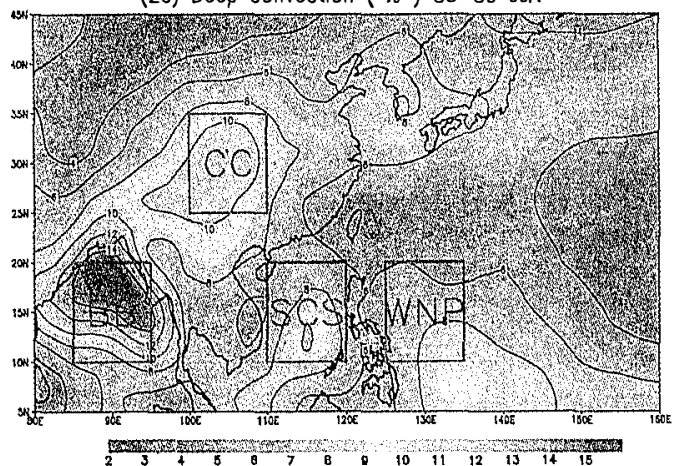

(2b) LW CRF ( w/m*m ) 85 89 JJA

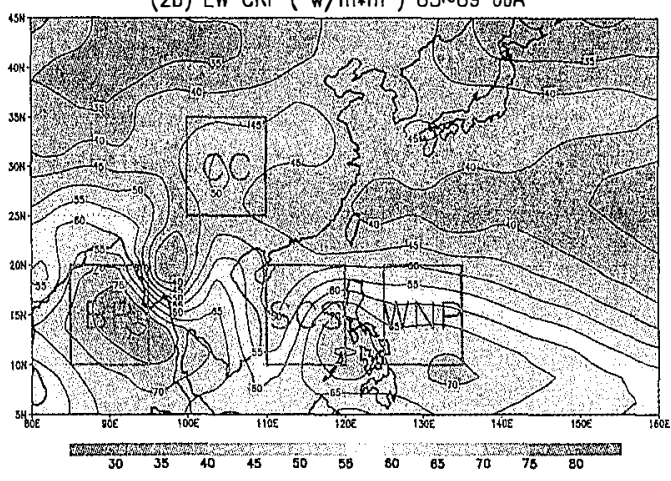

(2d) Precipitation Rate ( $\mathrm{mm} /$ day) 85 89 JJA

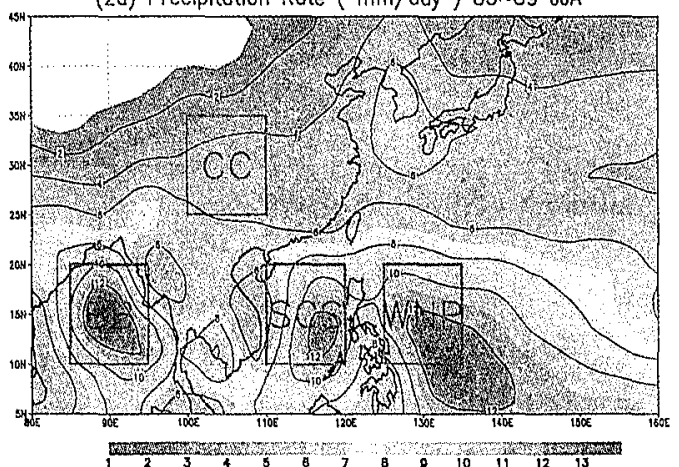

Fig. 2. The averaging distribution of (a) NCRF $\left(\mathrm{W} \mathrm{m}^{-2}\right)$, (b) LWCRF $\left(\mathrm{W} \mathrm{m}^{-2}\right)$, (c) deep convective cloud amount (\%), and (d) precipitation ( $\mathrm{mm} /$ day) during summer of the mean annual, readings from 1985 to 1989.

cloud amount (MCA+LCA), respectively. While Fig. 3c shows the monthly time series of $\mathrm{NCRF}$ and optical depth. As a monsoon region, it is apparent that the physical properties of clouds and radiation interactions related to circulation could have clear seasonal variation. All of the cloud components, OLR and precipitation in the ocean region of BB, SCS and WNP have similar phase structures during the seasonal cycle. The maximum TCA occurs during the APSM period and high clouds dominate the total cloud cover. Yet, the seasonal features of cloud cover in CC are complex (Fig. 3b2). The mid-low clouds rather than high clouds dominate the total cloud cover. Its maximum total cloud amount occurs in the spring. We can also find that during the APSM period, there is a positive correlation between the cloud optical depth and the mid-low cloud cover in CC. The small rectangle in Fig. 3b shows the variability of high cloud amount from June to August. Comparing BB with SCS and WNP in Fig. 3b, we can see that after the onset of the APSM, the high clouds persistently stay in BB with little variation in cloud amount, while in SCS and WNP the variability of high cloud amount are very large (i.e. short breaks for non-convective system occurs frequently). From Fig. 3c we 
can also see NCRF and optical depth have the same phase in BB. This indicates that, as the optical depth increases (because of the growing deep-convection), the NCRF will become largely negative (cooling). However, the optical depth over SCS and WNP are relatively small when compared with BB during the APSM period. The optical depth over CC is very different from three summer monsoon oceans.

Although they have the same large precipitations in the ocean regions of BB, SCS and WNP, their NCRF and optical depth are very different. In order to see more detail of this contrast we will examine the OLR and high cloud in these regions. The OLR in the convective region was specified to be lower than $220 \mathrm{~W} \mathrm{~m}^{-2}$ in this study. By using daily OLR, we can obtain the overall frequency distribution of the cloud cover. Fig. $4 \mathrm{a}$ is a frequency distribution of deep convection in each analysis regions from April to August. While Fig. 4b shows the average OLR strength of all points within Fig. 4a. Each region registers about 4500 readings every 30 days. From Fig. 4a, we can find that over BB, SCS and WNP, the deep convection rises sharply around late-May with the onset of Asian summer monsoon, while the deep convection in $\mathrm{CC}$ almost remains the same. From Fig. $4 \mathrm{~b}$ we can see that after the onset of the summer monsoon season the OLR drops sharply to around $175 \mathrm{~W} \mathrm{~m}^{-2}$ for the three ocean regions. At the same time, we can also find that in late July, the OLR in WNP can be less than $\mathrm{BB}$ and are associated with more heavy precipitation. This is consistent with LinHo and Wang (2002). They pointed out that the APSM has 2 monsoon outbreaks each marking a dry-wet cycle. The first cycle spans from the middle of May to early July and the second cycle from late July to early September. At the same time, the major convection center has also shifted from the adjacent seas in the northern Indian Ocean to the open ocean east of the Philippine Islands. Over $\mathrm{CC}$ we can find that the frequency of deep convection does not change during the whole summer.

The five-year mean annual cycle of the HCA averages over $10-20 \mathrm{~N}$ is shown in Fig. 5. It indicates that, after the first APSM outbreak (around mid-May), the strong deep-convection builds up over BB with the high cloud persisting for the whole summer and a magnitude that can exceed more than 65\%, while over SCS and WNP, the variation of high clouds become more random over time. After the onset of the second APSM outbreak (late July), the high cloud amount not only increases but also becomes more organized in WNP. It suggests that between the two monsoon outbreaks a brief recess of deep convection activity occurs over WNP.

To contrast the temporal variations of the HCA between BB and WNP, power spectrum analysis of the daily high cloud amount (from May to September) is applied. Null hypothesis for the significant test is the red noise whose spectral density and the corresponding values at the $95 \%$ percent interval are shown in Fig. 6 . The detail analysis procedures can be seen in Hsu and Weng (2002). Interestingly, the dominant periodicities of the BB and WNP disclose great differences. On one hand, from Fig. 6a we can see the leading peak of the BB is at a period of 75 days. The spectrum of the WNP (Fig. 6b), on the other hand, shows a prominent peak at 1020 days and the second distinctive peak at 8-9 days. These features are consistent with LinHo and Wang (2002), on the basis of OLR, they have pointed out that the SAC dominates in BB, while in WNP the FAC is more important than in BB. They also indicated that there have 8-9 days and biweekly westward propagation of rain movement over WNP, these 8-9 days and 
(3a) BD DLR\& PRPP B5-89
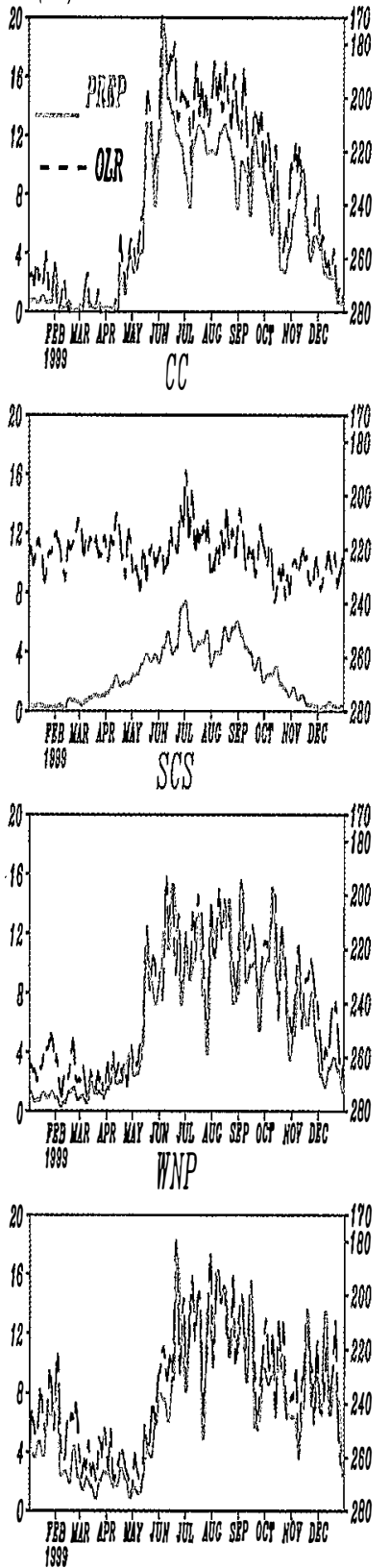

(30) BD ICA \& HCA \& ACACACCA

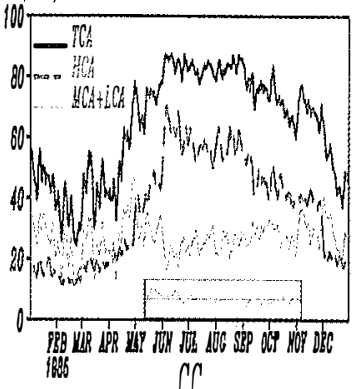

CC
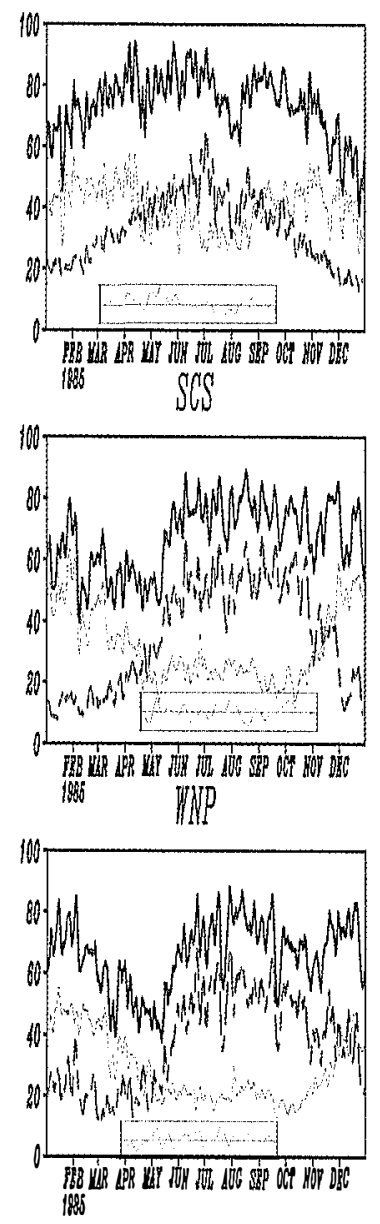

(3c) BB NCRP \& OD B5 B59 man
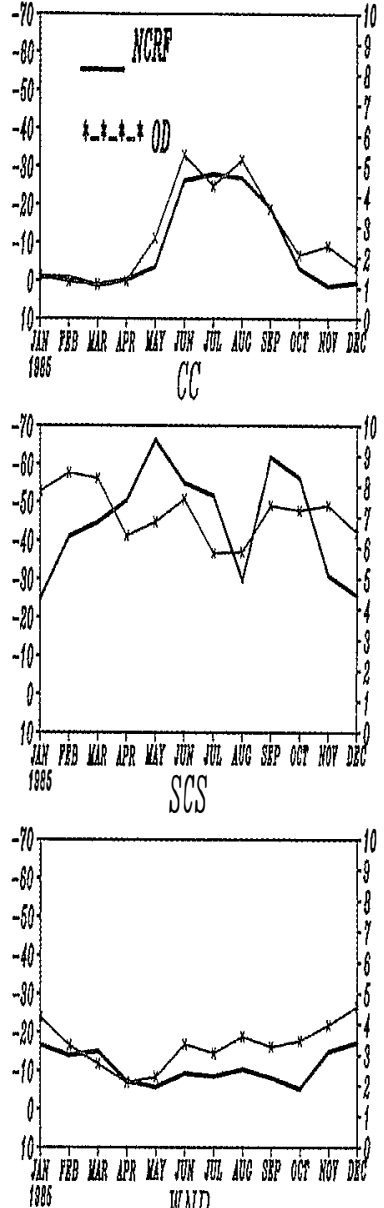

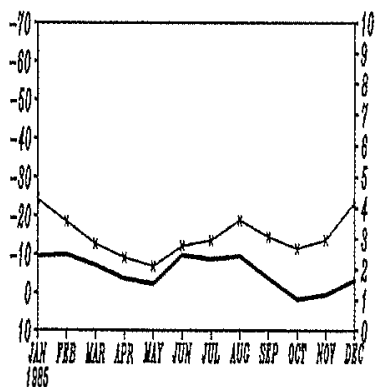

Fig. 3. Time series of the 1985-1989 mean annual cycle for the four analyzed regions: (a) OLR versus precipitation, (b) total cloud amount (TCA), high cloud amount (HCA) and mid+low cloud amount (MCA+LCA) (in units of \%). The small rectangle box in Fig. $4 \mathrm{~b}$ shows the variability of HCA from June to August. 

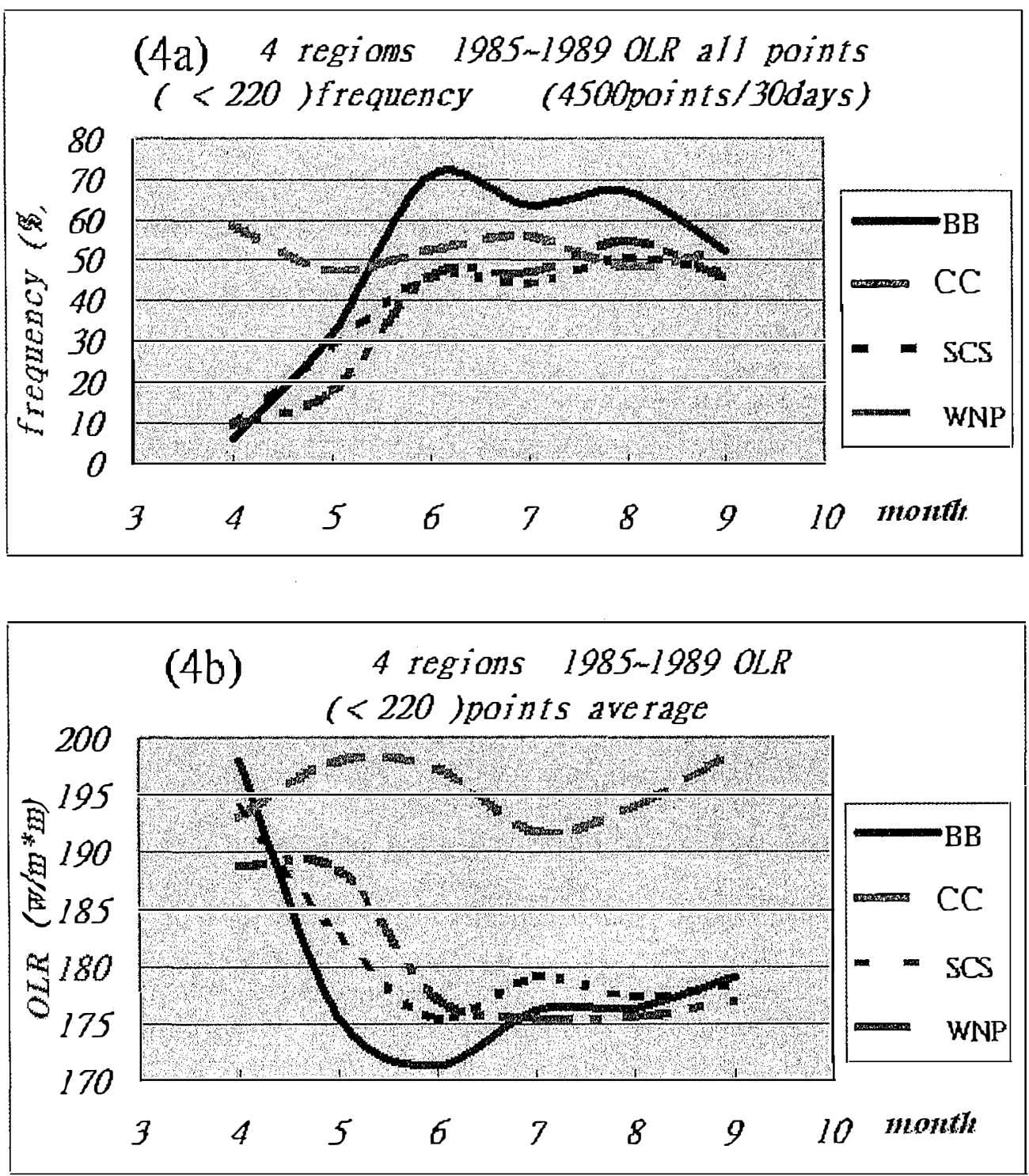

Fig. 4. The frequency distribution of deep convection in the analyzed regions with (a) the OLR less than $220 \mathrm{~W} \mathrm{~m}^{-2}$, and (b) its averaged OLR strength, the annual mean for the periods of June, July and August 1985-1989.

biweekly disturbances are primarily convectively coupled equatorial Rossby waves. Failure to simulate these two dominant periods may be the reason why the AGCMs exhibit great difficulty in reproducing correct precipitation in WNP. By using the GCM, Kau et al. (2003) have shown that, in order to have a better simulation of intra-season oscillation in the APSM, accurate simulation of the evolution of high clouds and cloud density are vital to the GCM.

In general, there are strong correlations among high cloud amount, OLR, and precipita- 
tion over deep convective systems in the Tropics. In order to see more clearly the relationship between OLR and high cloud amount in our analyzed regions, we have plotted the scatter diagrams of the OLR relating with high cloud amount in Fig. 7. It is obvious that the slope of HCA and OLR over CC is very different from other regions. From Fig. 7a we can see that the HCA seldom reaches $80 \%$ over BB; whereas, in SCS and WNP, we can find greater horizontal scatter for high cloud amounts exceeding $80 \%$, as well as more vertical scatter for the OLR at less than $160 \mathrm{~W} \mathrm{~m}^{-2}$ when compared with BB. This indicates that over BB the relationship between the higher HCA and lower OLR are more valid than over SCS and WNP (this may be due to the composition of high cloud are different between BB and both SCS and WNP). We can also find that for lower cloud amounts and higher OLR values (i.e. on the left-button corner), SCS and WNP both have more scatter points than in BB.

Although the NCRF over SCS and WNP are near zero, over BB it is largely negative (Fig. 2a). To aid the understanding of this discrepancy, Fig. 8 shows the scatter diagrams relating LWCRF and SWCRF, as well as cloud top pressure versus NCRF over the 4 analyzed regions. From Fig. 8a we can observe the cancellation of LW and SW when CRF occurs over SCS and WNP. However, over BB and CC the negative SWCRF is much larger than LWCRF. From Fig. 8b we can find that over SCS and WNP the NCRF is concentrated between -20 and $0 \mathrm{~W}$ $\mathrm{m}^{-2}$ with cloud top pressure extending over $310 \mathrm{mb}$; whereas in BB, the NCRF is more spread out with negative values (as low as $-80 \mathrm{~W} \mathrm{~m}^{-2}$ ), and has less vertical development of deepconvective cloud, with its cloud top pressures mostly under $310 \mathrm{mb}$. There may be two reasons for these features; (1) high cloud with thick optical depth (such as deep convective cloud) in BB plays a major role in the high cloud amount, and (2) high altitude anvil clouds with thin optical depth are more common in both WNP and SCS.

$\mathrm{CC}$ has more clouds with a cloud top pressure below $440 \mathrm{mb}$, and its NCRF is also more negative than over the ocean regions. This is consistent with Hahn et al. (2001). They pointed out that clouds over land have larger optical depths than clouds of the same type over ocean (due to a smaller averaged drop size rather than to a greater liquid water path).

A wide range of optical depths for convective tropical clouds with tops in the upper troposphere, such as thick anvil clouds near the convective cores to thin cirrus near its edges, show a wide range of net radiative forcing. Note that although the overcast cloud forcing for each individual cloud type can be strongly positive or negative, the ensemble of cloud types that occurs in association with deep convection arranges itself so that the individual positive and negative contributions cancel each other when averaged over the aggregate convective cloud system (Hartmann et al. 2001). In order to examine more details of the relationship between high cloud and CRF in the analyzed areas, we have plotted Fig. 9 to show the percentage of cirrus plus cirrostratus $(\mathrm{Ci}+\mathrm{Cs})$ cloud fraction to the high cloud amount from July to August. From Fig. 8 we can find over the three ocean regions, BB has the smallest percentage of $\mathrm{Ci}+\mathrm{Cs}$ while WNP has the largest and indicates that in $\mathrm{BB}$, the convection system has less $\mathrm{Ci}+\mathrm{Cs}$ with thin optical depths. In SCS and WNP, the ensemble of cloud types that occurs in association with deep-convection in higher altitudes has more optical thin anvil clouds. The variation of the averaged monthly percentage for the BB is $75 \%$ in June. It then increases to $81 \%$ in July and decreases to $77 \%$ in August, while Ci+Cs decreases slowly over WNP. This characteristic is obviously related to the two outbreaks of the APSM. Cess et al. (2001) pointed 
(5) HCA 10N $20 \mathrm{~N} 85-89$ daily ave

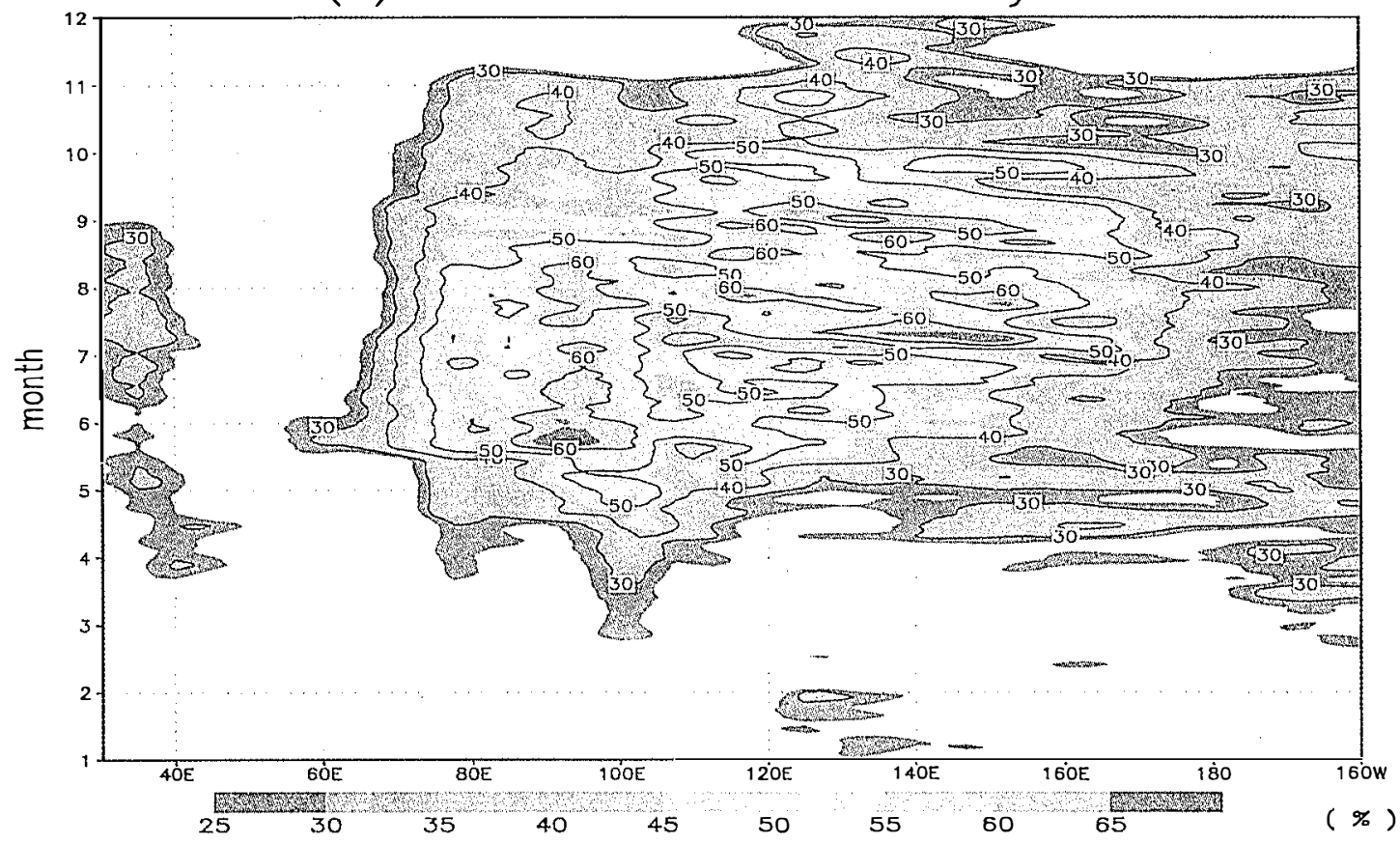

Fig. 5. The time series of the high cloud amount averaged over 10-20 $\mathrm{N}$ for the annual mean average from 1985-1989.

(6a) BB HCA 85 89 May-Sep Spectral Analysis

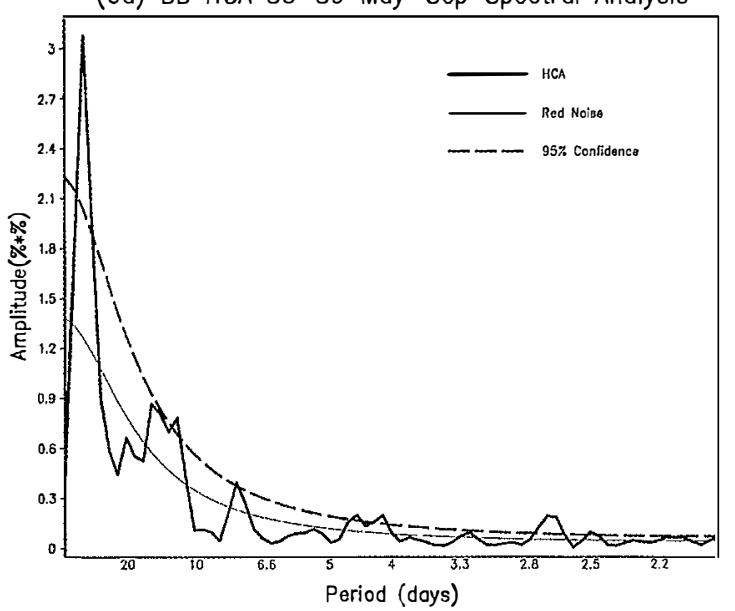

(6b) WNP HCA 85 89 May-Sep Spectral Analysis

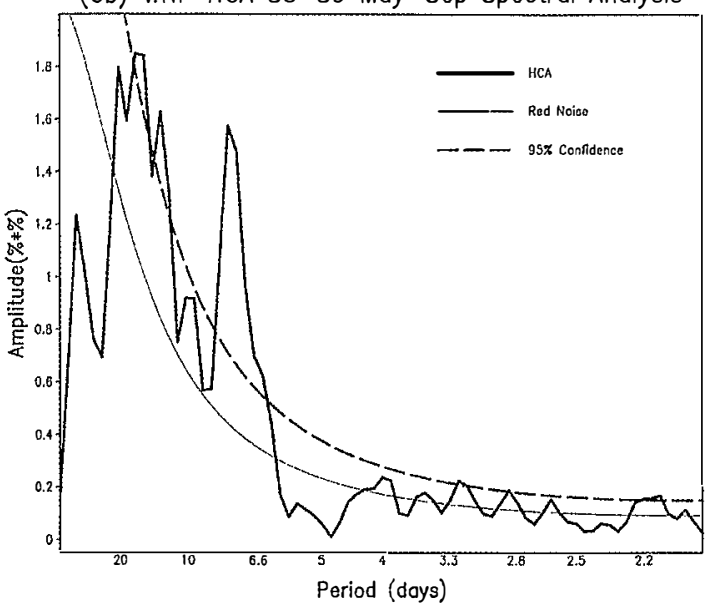

Fig. 6. Spectral density distribution of the detrended high cloud amounts at BB (6a) and WNP (6b). The solid curve represents the spectral density distribution of the red noise and the dashed curve indicates the corresponding values at the 95 percent confidence level. 
(7a) hca \& olr daily 85-89 jja BB ove

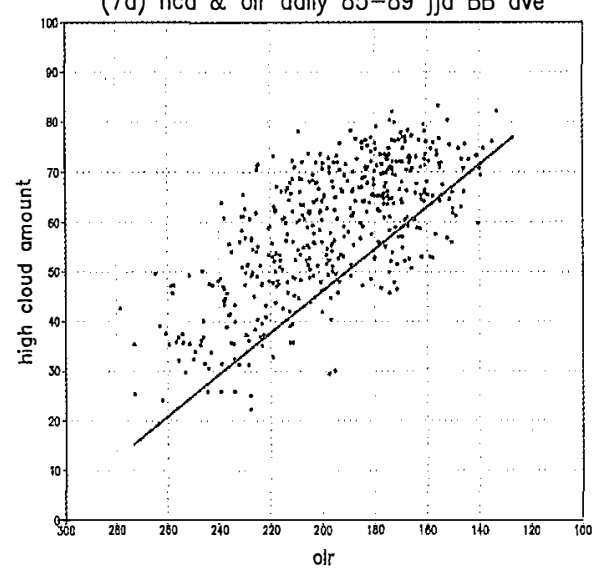

(7c) hca \& olr daily $85-89$ jja SCS ave

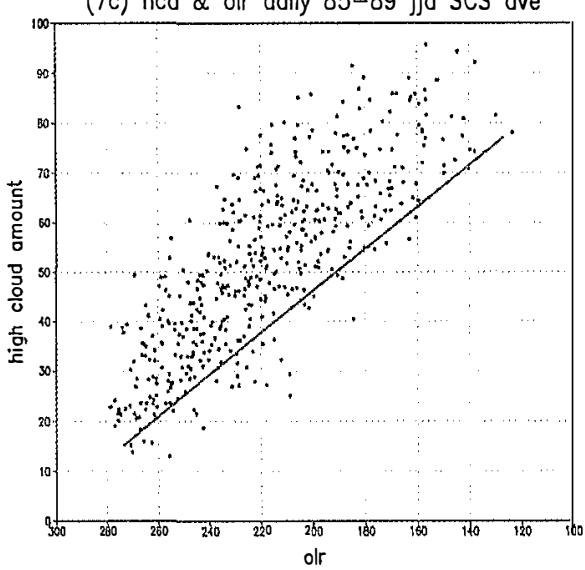

(7b) hca \& oir daily $85-89$ jja CC ave

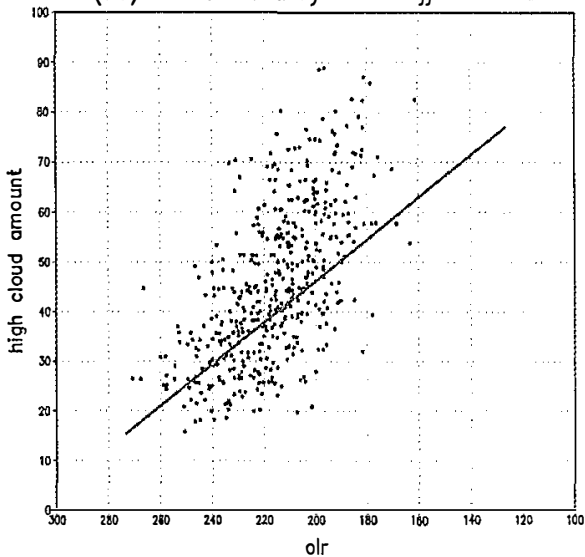

460 points

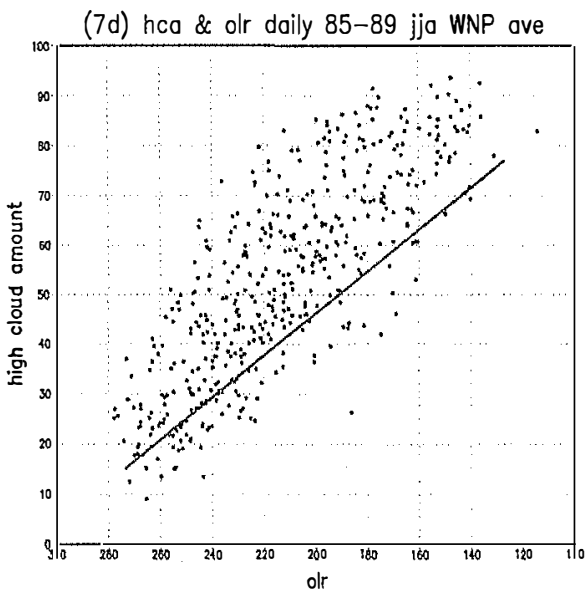

Fig. 7. Scatter-plots of OLR versus high cloud amount for the four analyzed regions during the JJA period.

out that for normal years as well as 1987, high clouds dominate the radiation budget over the warm pool. However, for the strong $1998 \mathrm{El} \mathrm{Niño,} \mathrm{the} \mathrm{measurements} \mathrm{indicate} \mathrm{the} \mathrm{radiation}$ budget is partially governed by middle-level clouds, thus explaining the net cooling over the warm pool during the $1998 \mathrm{El} \mathrm{Niño.} \mathrm{The} \mathrm{significant} \mathrm{difference} \mathrm{of} \mathrm{middle-level} \mathrm{clouds} \mathrm{be-}$ tween the BB and WNP is the Altostratus (optical depth ranges from 3.6 to 23). In the BB it occupies around $7.3 \%$ of the total cloud amount, while in the WNP's, it is only $3.5 \%$.

The five-year mean annual cycle of the CRF (the thick black line) for the analyzed regions are shown in Fig. 10. As expected, the three ocean regions have similar phase structures during the seasonal cycle for LWCRF, NCRF and SWCRF. From Fig. 10 we can find that BB has the largest negative SWCRF $\left(-120 \mathrm{~W} \mathrm{~m}^{-2}\right)$, which cause largely negative NCRF. In both SCS and WNP, the SWCRF is only around $-70 \mathrm{~W} \mathrm{~m}^{-2}$ and is cancelled out by LWCRF, makes NCRF close to zero. The reasons for the above characteristics can be explained by the following: 
Cess et al. (2001, Fig. 5a) pointed out that by using Fu and Liou's (1993) radiative-transfer model to calculate the CRF for a climatological mean tropical atmosphere and cloud optical depth increasing from a small value (thin cirrus), both cloud emissivity and cloud albedo simultaneously increase. As the cloud optical depth continues to increase (deep-convective clouds, optically thick) the cloud albedo increases more rapidly than does cloud emissivity, ultimately resulting in NCRF $<0$. This is consistent with Rajeevan and Srinivasan (2000) who show that the negative NCRF in the BB is due to the presence of larger amounts of high clouds and the thick optical depth of these clouds. These features can be also seen in Figs. 2, 3c, 4b and $8 \mathrm{~b}$. Further, the anvil cloud (below the tropopause) covers a large area and has a wide range of optical depths. The development of an extended anvil cloud is favored in areas of intense convection where convective updrafts are closely spaced (Houze 1993). Hartmann et al. (2001) introduced a simple model to prove cloud feedbacks processes that drive the net radiation in convective regions toward the net radiation in adjacent non-convective areas. They found that this model can predicts small NCRF by the convective cloud ensemble if the nonconvective regions have small CRF. Therefore, they suggested that the average TOA net radiation in most regions of deep convection in the Tropics does not differ from the net radiation in nearby regions of suppressed convection by more than about $10 \mathrm{~W} \mathrm{~m}^{-2}$. This occurs in part because variations in optically thick clouds are always accompanied by variations in optically thinner clouds. The radiation effects of the optically thick and thin clouds offset each other and the convective and non-convective areas are nearly in equilibrium with each other. This is the reason why WNP has a large variation of high clouds (Fig. 3b4) and the biggest $\mathrm{Ci}+\mathrm{Cs}$ percentage in high cloud amount (Fig. 9). However, if the convective cloud is influenced by the strong dynamic forcing with heating over the Asian landmass during the summer, such as in the $\mathrm{BB}$ area, then the NCRF in the convective regions can be significantly negative.

The CRF between CC and BB is very different and is mainly due to the land/sea contrast. Based upon their cloud properties, we can also tell the reasons for these discrepancies. CC has thick optical depth and big deep convective cloud fractions (Fig. 2c) as in BB. Nevertheless, mid+low cloud types instead of high cloud make a major contribution to the large optical depth in CC (Fig. 8b2). Therefore, due to the fact that middle level clouds are warmer and have smaller LWCRF while at the same time optically thick clouds will produce larger negative SWCRF, they will cause the NCRF to become closely related to SWCRF (Fig. 10b).

\subsection{Circulations Related to the Cloud Properties}

Over India, the meridional land-sea thermal contrast and the effects of the elevated Tibetan Plateau heat source reinforce the inter-hemispheric thermal contrast derived from differential solar radiation, resulting in an extremely energetic southwesterly monsoon. In conjunction with the influence of the north-south differential solar forcing and the east-west landocean thermal contrast, the WNP monsoon trough directly controls summer rainfall in a vast oceanic region of the WNP (Wang and LinHo 2002). We may use climatological divergence circulation evidence to relate the CRF to the analysis of the regions, especially during the APSM period. Fig. 11 shows the time-height cross section of climatological horizontal divergence. In the high levels (above $200 \mathrm{mb}$ ), all of the four regions have similar seasonal 

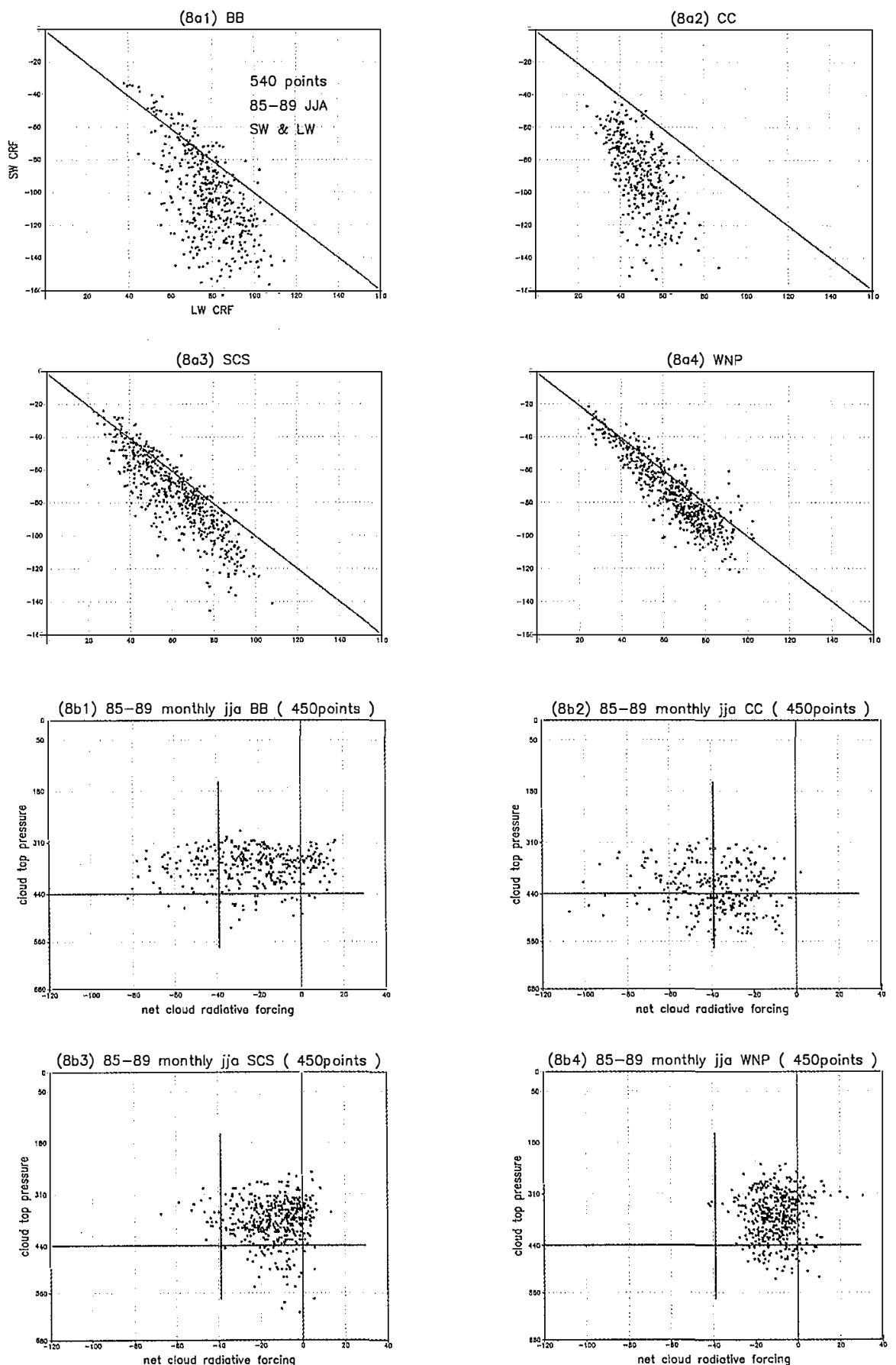

Fig. 8. Same as Fig. 7 except for (a) short-wave cloud radiative forcing versus long-wave cloud radiative forcing, and (b) cloud top pressure and net cloud radiative forcing. 


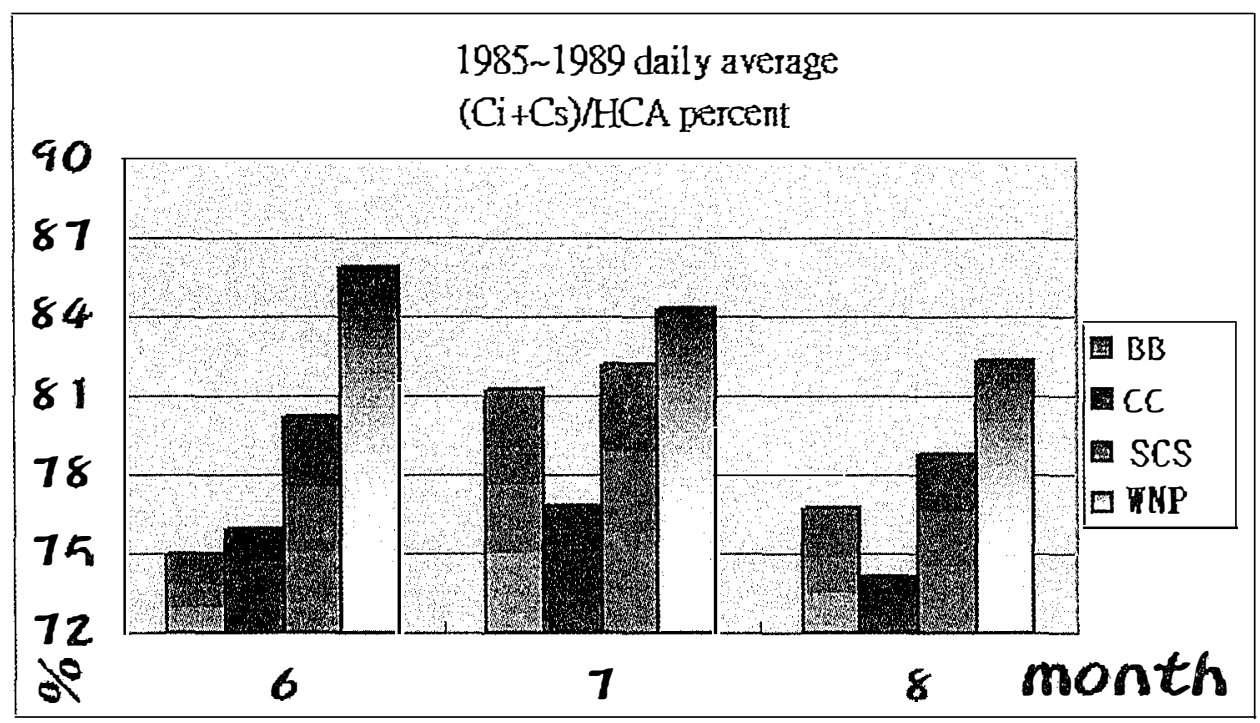

Fig. 9. The percentage of cirrus plus cirrostratus in high cloud amount of the four analyzed 4 regions during the months of June, July and August.
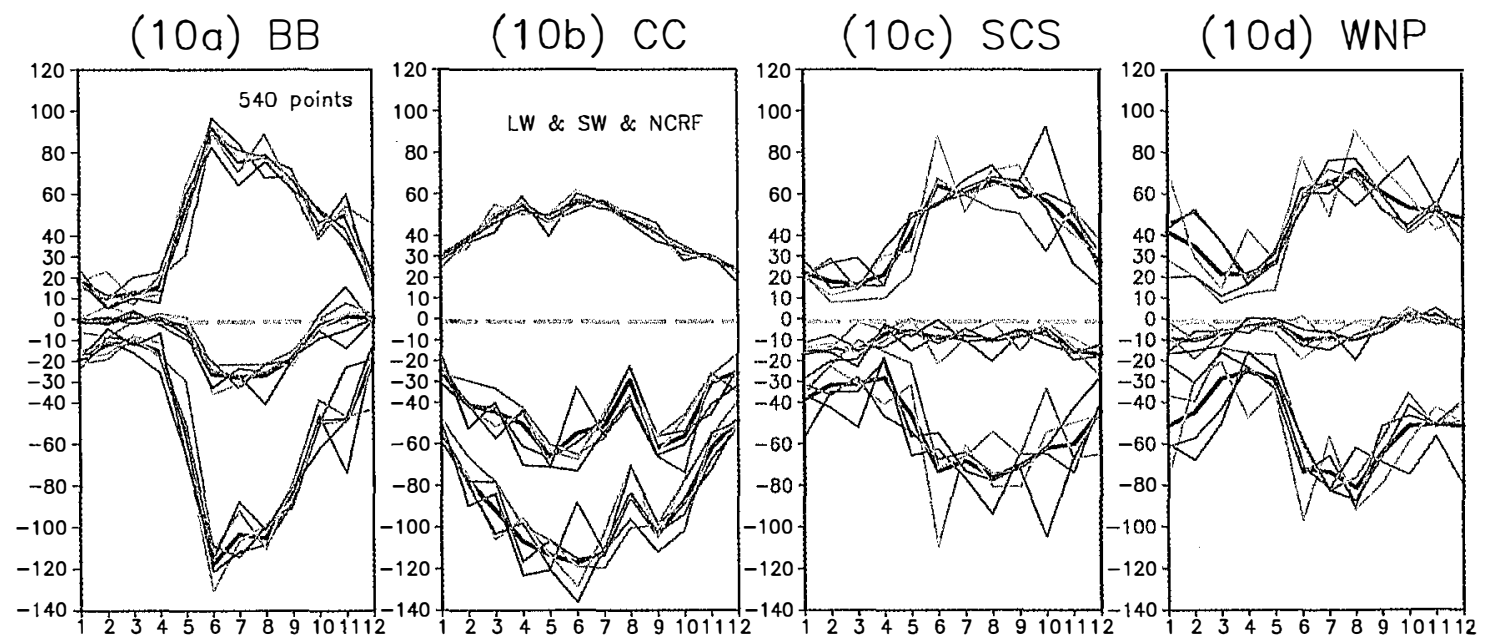

Fig. 10. The distribution of five-year (1985 to 1989) and its mean annual cycle (thick line) of the cloud radiative forcing for the 4 analyzed regions. Longwave cloud radiative forcing is positive, shortwave cloud radiative forcing is negative, and the net cloud radiative forcing is the sum of these two values. 
cycles with divergence in the summer season and convergence during the winter. However, there is a stronger divergence in the summer for three ocean regions. Below $700 \mathrm{mb}$, the divergence found in the 3 ocean regions have a reversed pattern when compared to higher levels. Converging features persist throughout the year with the strongest convergence in spring above CC. The divergence structure in the 3 ocean regions behave in a see-saw pattern, but in the $\mathrm{CC}$, two convergence layers are in the higher and lower troposphere, respectively, with a divergence layer in the middle troposphere. The large-scale circulation, which is responsible for this type of divergence structure, determines the seasonal cycle and cloud fraction. In BB, SCS and WNP, it is only in summer season that large-scale circulation results in a strong convergence in the lower layer and divergence over higher layer, activating the deep convection. The low level convergence coupled with upper level divergence in the BB is very strong and persists for the whole summer. While this kind of system in both SCS and WNP are much weaker than in BB, it maintains its maximum intensity only until August. Note that surrounding the region of increased deep convection (associated with strong divergence at upper level) are areas of intensified subsidence. The stronger than average sinking motion inhibits the formation of the high thin clouds that are normally present. This is the reason that caused the fraction of $\mathrm{Ci}+\mathrm{Cs}$ to be less in $\mathrm{BB}$ than in WNP. Through the power spectrum analysis of the daily $850 \mathrm{mb}$ convergence circulations (not shown), as we did in the previous section for high cloud amounts, we can find the spectrum of the WNP shows two distinctive peaks around 20 days and 9 days respectively. These two dominant frequencies are almost coincided with the leading frequencies from high cloud amounts' analysis (Fig. 6b), indicating the $850 \mathrm{mb}$ convergence and high cloud amount have very close temporal relationship over WNP. In CC, large cloud fraction might persist through all seasons and correspond to the lower layer
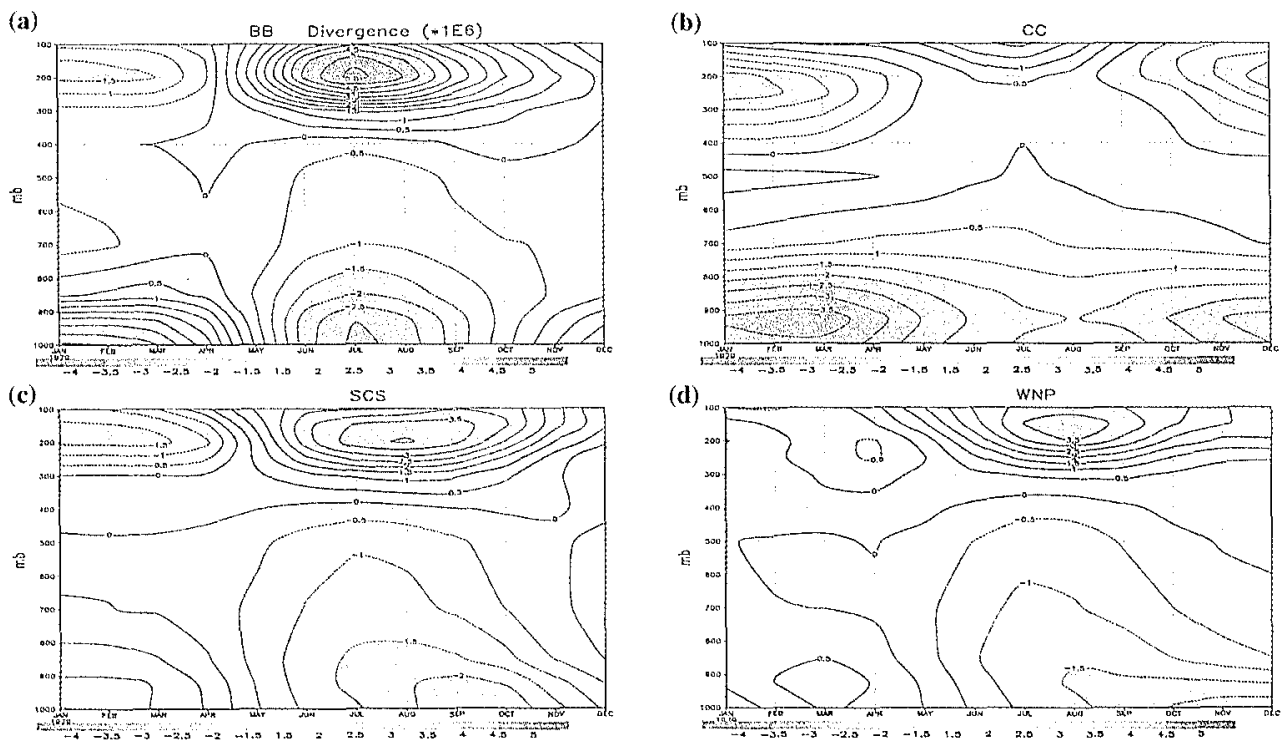

Fig. 11. Time-high cross section of horizontal divergence (in units of 10E6), for the 4 analysis regions. 
convergence, but in the winter season, the stronger mid-layer divergence limits the clouds towering at high level, so a coherent mid-cloud dominates the cloud fraction.

\section{CONCLUSION}

Clouds have been shown to be one of the most important factors regulating the current climate system and future climate change. Year to year changes of cloud amount can contribute to fluctuations in the global climate system. The CRF at TOA provides a useful measure of the influence of clouds on radiation energy. The CRF exhibits significant seasonal and geographic variability. The geographic distributions of the onset, retreat, and peak of the rainfall annual cycle exhibit remarkable regionalitly among the three monsoon subsystems - the IM, WNPM, and EAM. LinHo and Wang (2002) pointed out that the APSM climatology is characterized by a slowly evolving seasonal transition (SAC) superimposed upon two FACs. They also showed that the ratio of FAC to SAC reveals that the SAC dominates in the BB, while the FAC has a more powerful presence than SAC in the WNP. Wang et al. (2002) examined the precipitation rate averaged over the IM and WNPM regions during APSM period from 11 AGCMs. They pointed out that over the IM region nearly all models overestimate the summer precipitation rate. On the other hand, over the WNPM region, none of the models were close to the all-model mean. They reconfirmed that the "AGCMs exhibit great difficulty in reproducing correct climatology in WNP than over the Indian region" by Kang et al. (2001). They attribute this inept performance to the neglect of monsoon-ocean interaction in the AGCMs, since clouds are import because they both affect and are affected by variations of SST. We therefore attribute this deficiency to the inaccurate simulations of the distribution and radiative properties of clouds by GCMs. Investigating the APSM becomes all the more important because the study of the CRF in the APSM region (especially between BB and WNP) will not only provide us more information about the relationship between large-scale circulations and CRF but also help to improve the quality of CRF simulations in the AGCM (Kau et al. 2003).

In this study, we combined ERBE and ISCCP-D1 data to inquire about some relative properties of CRF over APSM region. The primary conclusions of this study are summarized as follows.

(1) OLR, cloud radiative forcing, total cloud amount, high-level cloud amount, middlelevel cloud amount and precipitation all have similar phase structures during a seasonal cycle over the ocean regions of BB, SCS and WNP, but not over the land mass of CC. During the APSM period, the OLR drops more sharply than in other seasons, while precipitation, cloud amounts and CRF all increase rapidly over three oceanic regions.

(2) In general, there are strong correlations among high cloud amounts, OLR, and precipitation over the three ocean regions. During the APSM period, high clouds dominate the total cloud amount and NCRF correlates well with the optical depth over these three oceanic regions. Nevertheless, $\mathrm{CC}$ is quite different from ocean regions because its mid-low clouds play more important roles than high cloud and thus provide much useful information as a baseline comparison of the oceanic data.

(3) China's land mass and BB both have thick cloud optical depths and large deep-con- 
vective cloud amounts, but less precipitation and a smaller LWCRF occur over CC. These discrepancies are due to very different temporal and spatial distributions of cloud types in these two regions. The peculiar characteristics of cloud properties and CRF compared between land and ocean analyses need further study.

(4) We know that a near cancellation between LWCRF and SWCRF effects at TOA is a fundamental feature of deep convective systems in the Tropics but has been shown to be invalid over the BB region (due to the large amount of high cloud with thick optical depth as well as strong dynamical forcing associated with closely spaced convective updrafts). The NCRF can be as low as $-40 \mathrm{~W} \mathrm{~m}^{-2}$ in BB. While in both SCS and WNP, individual elements within the convective cloud system show a wide range of net radiative forcing (from the thick anvil clouds near convective cores to thin cirrus clouds near the edges of the anvil cloud). Interestingly, the cloud ensemble of these cloud types produces an average net radiation change near zero, as pointed out by Hartmann et al. (2001).

(5) After the onset of the summer monsoon (about mid-May), there is a lower OLR and great cloud amounts with heavy and persistent rainfall in BB throughout the whole summer. While SCS and WNP are different from BB, a brief recess of deep convection occurs in midJuly. This causes the magnitude of precipitation, cloud amount, optical depth and CRF for the entire summer average in SCS and WNP to be less than in BB. However, the precipitation, optical depth and low OLR strength are stronger after second monsoon outbreak (about lateJuly). For example, the optical depth of deep-convection can reach 70 in the WNP.

(6) Power spectrum analysis of daily mean time series (May to September) of the high cloud amounts over the BB and WNP discloses differing dominant periodicities. The highest power spectrum over the BB is around a 75 day period, which is in the intra-season timescale. On the other hand, in the WNP the significant spectral peaks have moved to 10-20 day and 89 day periods, indicating the FAC has a powerful presence. These 10-20 day and 8-9 day periods may be related to the westward propagation of rain movement over the WNP, as mentioned by LinHo and Wang (2002). Failure to simulate these two dominant periods may be the reason why the AGCMs exhibit great difficulty in reproducing correct precipitation in WNP (kau et al. 2003).

(7) When analyzing each of the summer monsoon oceans, each display a deep convective system developed by a strong convergence in low level and coupled with the divergence in the higher altitudes during JJA. The low level convergences in the BB are very strong and persist for the whole summer. While this convergence in the SCS and WNP is much weaker than in $\mathrm{BB}$, it reaches maximum intensity only until August. These are consistent with the temporal evolution of the high cloud amount as mentioned in (6). The circulation patterns over CC are very different from the ocean regions. In the $\mathrm{CC}$, converging features persist throughout the year with the strongest convergence in the spring. By combining the climatological divergence circulations, CRF, as well as the clouds' vertical and horizontal distributions during the APSM period, we can illustrate with schematic diagrams the cloud radiative forcing over the BB and WNP, as in Fig.12. The different cloud types are indicative of the dynamic and thermodynamic state of the atmosphere and also have quite different radiative effects. Those features are very obvious in Fig. 12, which make the cloud radiative forcing over WNP dissimilar from $\mathrm{BB}$. 
$B B$

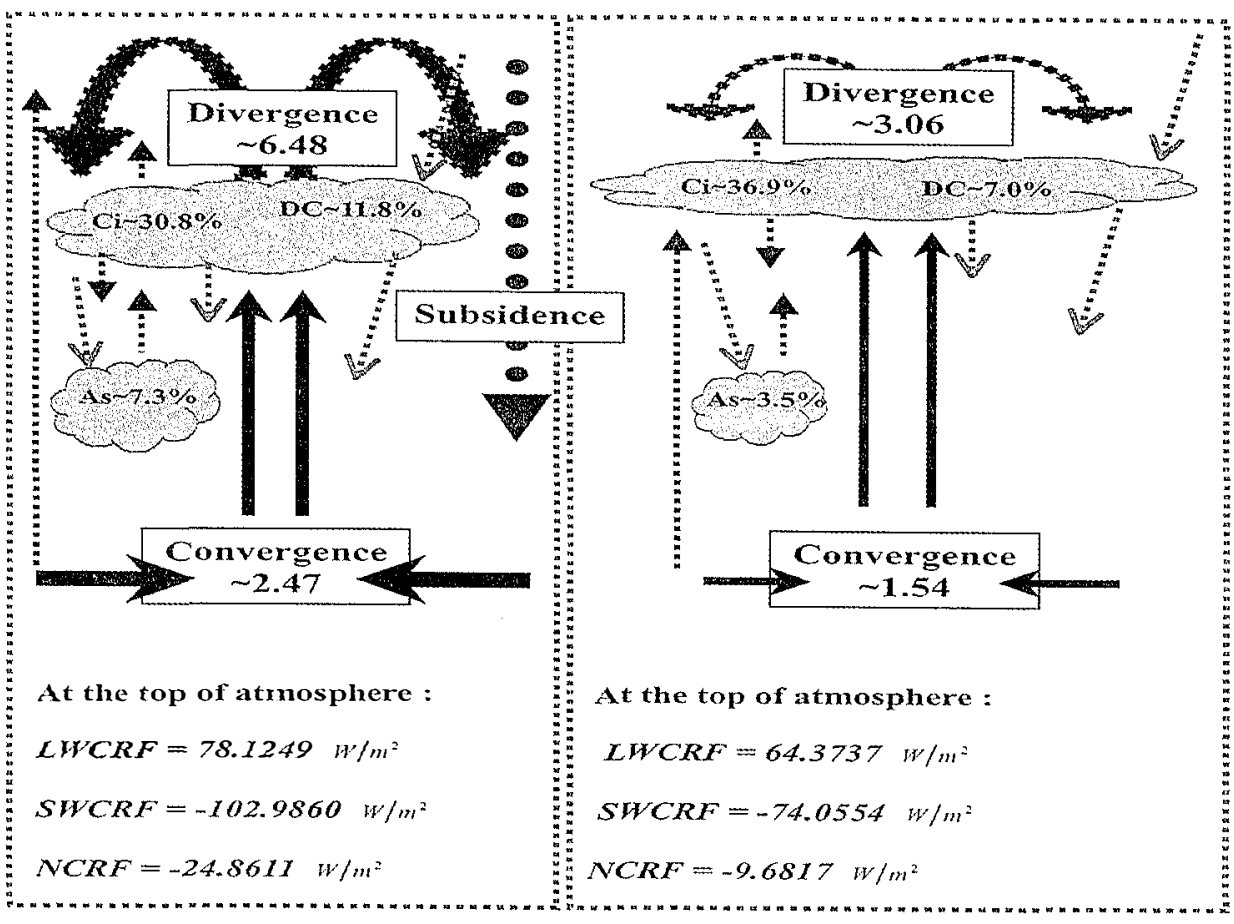

Fig. 12. The schematic diagram of cloud radiative forcing associated with its circulations over the Bay of Bengal and the western North Pacific.

Visible optical depths of common convective cloud types in the upper tropical troposphere range from 1 to 60 (Hartmann et al. 2001). The corresponding NCRF at TOA for these cloud types range from +20 to $-119 \mathrm{~W} \mathrm{~m}^{-2}$. This great variation in NCRF arises mostly from the reflectivity of the clouds. Many climate models are now being introduced that include predicted rather than diagnostic cloud optical properties. However, inaccurate simulations of the distribution and properties of clouds mean that the magnitude changes in cloud radiation effects and related to local changes in the dynamic regime may still be poorly simulated. The solution for the problem of clouds in climate depends on the success of constructing a physically based cloud formation model that can effectively couple with GCMs. Given the uncertainty in cloud feedbacks and their importance with respect to future climate predictions, the observed cloud forcing and its variability provide an important means of testing and improving climate models. Further detailed diagnostic studies along the lines of the present study need to be carried out.

Acknowledgments The author benefited from discussions with Professors Lin Ho and $\mathrm{H}$. $\mathrm{H}$. Hsu. Gratitude is also extended to two anonymous reviewers for their helpful comments on the manuscript. This study was supported by the National Sciences Council of the R.O.C., under NSC91-2111-M-002-018, NSC90-2111-M-002-020-AP1 and NSC 90-2621-Z-002-011. 


\section{REFERENCE}

Allan, R. P., A. Slingo, and M. A. Ringer, 2002: Influence of dynamics on the changes in tropical cloud radiative forcing during the 1998 El Niño. J. Climate., 15, 1979-1986.

Bergman, J. W., and H. H. Hendon, 2000: The impact of clouds on the seasonal cycle of radiative heating over the Pacific. J. Atmos. Sci., 57, 545-566.

Cess, R. D., M. Zhang, B. D. Wielicki, D. F. Young, X. L. Zhou, and Y. Nikitenko, 2001: The influence of 1998 El Niño cloud-radiative forcing over the Pacific warm pool. Amer. Meteor. Soc., 14, 2129-2137.

Chen, J., B. E. Carlson, A. D. Del Genio, 2002: Evidence for strengthening of the tropical general circulation in the 1990s. Science, 295, 838-840.

Fu, Q., and K. N. Liou, 1993: Parameteriations of the radiative properties of cirrus clouds. $J$. Atmos. Sci., 50, 2008-2025.

Hahn. C. J., Rossow, W. B. Warren, and S. G., 2001: ISCCP Cloud Properties Associated with Standard Cloud Types Identified in Indiviual Surface Observation. Amer. Meteor. Soc., 57, 11-28.

Hartmann, D. L., and D. A. Short, 1980: On the use of earth radiation budget statistics for studies of clouds and climate. J. Atmos. Sci., 37, 1233-1250.

Hartmann, D. L., and D. Doelling, 1991: On the net radiation effectiveness of clouds. $J$. Geophys. Res., 96, 869-891.

Hartmann, D. L., L. A. Moy, and Q. Fu, 2001: Tropical convection and the energy balance at the top of the atmosphere. Amer. Meteor. Soc., 14, 4495-4511.

Houze, R. A., Jr., 1993: Cloud Dynamics., Academic Press, 576 pp .

Hsu, H. H., and S. P. Weng, 2002: Stratospheric Antarctic Intraseasonal Oscillation during the Austral winter. J. Meteor. Soc. Japan, 80, 1029-1050.

Kang, I-S, and Coauthors, 2001: Intercomparison of GCM simulated anomalies associated with the 1997-98 El Niño. Climate Dyn., in press

Kau, W. S., C. H. Wu, C. H. Tsou, and C. H. Tu, 2003: The simulation studies of cloud/ radiation effect to the low frequency oscillation during East Asian Summer Monsoon. Atmos. Sci., 31, 159-180. ( in Chinese with an English abstract).

Kessler, W. S., L. M. Rothstein, and D. Chen, 1998: The annual cycle of SST in the eastern tropical Pacific diagnosed in an ocean GCM. J. Climate, 11, 777-499.

Kiehl, J. T., 1994: On the observed near cancellation between longwave and shortwave cloud forcing in tropical regions. Amer. Meteor. Soc., 7, 559-565.

Lanzante, J. R., 1983: Some singularities and iiregularities in the seasonal progression of the $700 \mathrm{mb}$ height field. J. Climate Appl. Meteor., 22, 967-982.

LinHo, and B. Wang, 2002: The time-space structure of the Asian-Pacific summer monsoona fast annual cycle view. J. Climate., 15, 2001-2019.

Ma, C.-C., R. Mechoso, A. W. Robertson, and A. Arakawa, 1996: Peruvian stratus clouds and the tropical Pacific circulation: A couple ocean-atmosphere GCM study. J. Climate, 9, 1635-1645.

Neelin, J. D., and I. M. Held, 1987: Modeling tropical convergence zone based on moist static 
energy budget. Mon. Wea. Rev., 115, 3-12.

Pai, D. S., and M. Rajeevan, 1998: Clouds and cloud radiative forcing over tropical Indian Ocean and their relationship with sea surface temperature. Curr. Sci., 75, 372-381.

Rajeevan, M., and J. Srinivasan, 2000: Net cloud radiative forcing at the top of atmosphere in the Asian Monsoon Region. J. Climate., 13, 650-657.

Randall, D. A., Harshvardhan, D. A. Dazlich, and T. G. Corsetti, 1989: Interactions among radiation, convection, and large-scale dynamics in a general circulation model. J. Atmos. Sci., 46, 1943-1970.

Rieland, M., and E. Raschke, 1991: Diurnal variability of the earth radiation budget: Sampling requirements, time integration aspects and error estimates for the Earth Radiation Budget Experiment (ERBE). Theor. Appl. Climato., 44, 9-24.

Sherwood, S. C., V. Ramamnathan, T. P. Barnett, M. K. Tyree, and E. Poeckner, 1994: Response of an atmospheric general circulation model to radiative forcing of tropical cloud. J. Geophys. Res., 99, 20829-20845.

Slingo, J. M., and Slingo, 1991: The response of a general circulation model to cloud longwave forcing. II: Further studies. Q. J. R. Meteorol. Soc., 117, 333-364.

Tao, S., and L. Chen, 1987: A review of recent research on the East Asian summer monsoon in China. Monsoon Meteorology, C.-P. Chang and T. N. Krishnamurti, Eds., Oxford University Press, 60-92.

Tian, B., and V. Ramamnathan, 2002: Role of Tropical Clouds in Surface and Atmospheric Energy Budget. J. Climate, 15, 296-305.

Trenberth, K. E., 2002: Changes in tropical clouds and radiation. Science, 296, $2095 \mathrm{a}$.

Wang, W-C., W.-S. Kau, H.-H. Hsu, and C.-H. Tu, 2003: Characteristics of cloud radiative forcing over East Asia. J. Climate, EAC Special Issue (in press).

Wang, B., R. Wu, and K.-M. Lau, 2001: Interannual variability of the Asian summer monsoon: Contrasts between the Indian and the western North Pacific-East Asian monsoon. $J$. Climate, 14, 4073-4090.

Wang, B., and LinHo, 2002: Rainy Season of Asian-Pacific Summer Monsoon. J. Climate, 15, 386-398.

Weare, B. C., 1997a: Climatic variability of cloud radiative forcing. Quart. J. Roy. Meteor. Soc., 123, 1055-1073.

Weare, B. C., 1997b: Comparison of NCEP-NCAR cloud radiative forcing reanalyzes with observations. J. Climate, 10, 2200-2209.

Wielicki, B. A., T. Wong, R. P. Allan, A. Slingo, J. T. Kiehl, B. J. Soden, C. T. Gordon, A. J. Miller, S. K. Yang, D. A. Randall, F. Robertson, J. Susskind, and H. Jacobowitz, 2002: Evidence for large decadal variability in the tropical mean radiative energy budget. Science, 295, 841-844.

Yu, Rucong, M. Zhang, and R. D. Cess, 1999: Analysis of the atmospheric energy budget: A consistency study of available data sets. J. Geopys. Res., 108, No. D8, 9655-9661. 